\title{
A Comparative Radiographic Evaluation of Crestal Bone Resorption in Single Implant versus Two Implant Retained Mandibular Overdentures - A Randomised Controlled Trial
}

\author{
Dr. Kumar Ravishankar ${ }^{1}$, Dr. Raja Singh ${ }^{2}$, Dr. Tanu Raghav ${ }^{3}$, Dr. Mamta Singh ${ }^{4 *}$, Dr. Meenakshi M. Singh ${ }^{5}$ \\ ${ }^{1}$ Senior lecturer (MDS), Department of Periodontology, Aditya Dental College, Beed- 431122 \\ ${ }^{2}$ Third Year Postgraduate Student, Department of Prosthodontics and Crown and Bridge, Subharti Dental College, Swami Vivekanand \\ Subharti University, Meerut, U.P. India \\ ${ }^{3}$ Third Year Postgraduate Student, Department of Prosthodontics and Crown and Bridge, Subharti Dental College, Swami Vivekanand \\ Subharti University, Meerut, U.P. India \\ ${ }^{4}$ Senior Lecturer Department of Periodontics, Kothiwal Dental College and Research Centre, Mora Mustaqueem, Kanth Road, \\ Moradabad, 244001, India \\ ${ }^{5}$ Post Graduate Trainee Third Year, Department of Pedodontics and Preventive Dentistry, Kothiwal Dental College and Research \\ Centre, Mora Mustaqueem, Kanth Road, Moradabad, 244001, Uttar Pradesh, India
}

Article History

Received: 22.11 .2020

Accepted: 07.12.2020

Published: 23.12.2020

Journal homepage:

https://www.easpublisher.com

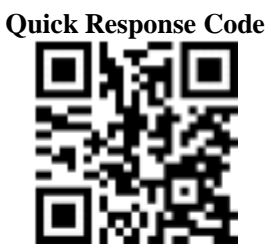

Abstract: Aim: The aim of present study was to evaluate and compare radiographically the amount of crestal bone resorption during healing and loading period in single implant versus two implant retained mandibular overdentures in totally edentulous patients. Materials \& Methods: A total of 20 edentulous patients (12 male and 8 female) with age range of 58.6 years were included in this clinical trial which was completed in 4 phases (clinical and radiographic diagnosis, surgical phase, implant loading phase and bone level measurement phase). The eligible patients were randomly allocated in 2 equivalent groups of 10 participants each per group. The allocation was in 1:1 ratio via randomized chit method. Group I included the case group i.e. single implant and Group II included the control group i.e. two-implants located in mandible. A total of 30 implants were placed in Group I and 20 implants in Group II. Digital intraoral peri-apical radiographs (RVG 5100) were used for measuring the bone level immediately after implant surgery, 1 month, 3 months, 4months and 6 months. Result: The present study showed that there was a mean crestal bone loss of $0.7 \mathrm{~mm}$ between the tip of the implant and alveolar crest at the end of 6 months after implant placement in single implant group I while $0.67 \mathrm{~mm}$ in case of Group II two-implant retained mandibular overdentures. The percentage of crestal bone loss after 6 months follow up was $6.45 \%$ which is in Group I which was statistically insignificant compared to crestal bone loss in seen in Group II wherein $6.25 \%$ of bone loss was recorded. Conclusion: Single implant retained mandibular overdentures could be used as another alternative treatment option for completely edentulous elderly patients with severely resorbed ridges and financially and systemically compromised conditions.

Keywords: Edentulous; Overdenture; Intraoral Periapical (IOPA); Crestal bone loss.

Copyright (C) 2020 The Author(s): This is an open-access article distributed under the terms of the Creative Commons Attribution 4.0 International License (CC BY-NC 4.0) which permits unrestricted use, distribution, and reproduction in any medium for non-commercial use provided the original author and source are credited.

\section{INTRODUCTION}

Crestal bone resorption is a common biological complication associated with dental implant failure. The amount of crestal bone loss is maximum in first year during healing and loading period. Implant-retained overdentures are widely used for the rehabilitation of edentulous jaws to increase retention of prosthesis, to enhance the masticatory function and reduce the absorption of alveolar bone by regulating neuromuscular adaptation.1 Rehabilitation of edentulous patients become even more difficult in cases of advanced ridge resorption in mandibular edentulous cases. It is very difficult to rehabilitate an edentulous patient with a compromised mandibular alveolar bone because it often results in denture soreness, poor retention \& stability along with improper speech and low chewing efficiency. The York consensus statement recommends at least two implants to support mandibular overdentures for edentulous patients. However, economic constraints especially among the emerging elderly population in developing countries make ours treatment strategy financially is challenging. 
In order to reduce the cost and time of treatment, the concept of single implant retained overdentures provides another option for elderly populations [1].

The longevity and success of dental implants with prosthesis is highly dependent on integration between implant components and oral tissues, including hard and soft tissues. Initial breakdown of the implanttissue interface generally begins at the crestal region in successfully osseointegrated endosteal implants. In particular, after the first year of function, crestal bone loss upto or beyond the first thread of titanium screw implants, characterized by "saucerization," is often observed radiographically around certain implant types [2]. Many possible etiologies of early crestal bone loss around implants (from implant placement to 1-year post-loading) including surgical trauma, occlusal overload, peri-implantitis, the presence of microgap, reformation of biologic width, implant crest module and others have been proposed. However, the location of dental implants, whether subcrestal or supracrestal, is still becoming increasing importance for researchers [3].

Enough evidence is available to advocate the hypothesis that a two-implant supported mandibular overdenture is the first choice of treatment for edentulous patients $[4,5]$. But, the low economic status of developing countries serves the major constraint. Hence, the use of single-implant concept was introduced to stabilize the lower denture. It served as a better alternative to two implant supported mandibular overdenture [6].

Single-implant mandibular overdentures concept may be of beneficial effect on geriatric population regarding the health and financial status. Problems encountered with two implant retained overdentures like both implants should be parallel to each other, should be equidistant from the midline \& should be at same level to each other and failure of one may lead to unequal stresses on the other. All these can be avoided in case of single implant retained overdentures [7]. Nevertheless, this concept needs wellorganized controlled trials to evaluate all aspect of patients oriented and functional outcomes.

The present study was thus designed to radiographically evaluate and compare the amount of crestal bone resorption in both thus determining the long-term success of two systems.

\section{Materials \& MethoD}

The present randomized controlled trial was carried out in the Department of Prosthodontics and Crown \& Bridge in collaboration with Department of Oral Medicine, Diagnosis \& Radiology and Department of Oral \& Maxillofacial Surgery, to evaluate the crestal bone loss in a single implant versus two implant retained mandibular overdentures opposing a maxillary complete denture over a period of 6 months follow-up after implant placement.

\section{Study Design}

Study was designed to be a randomized clinical trial (RCT), two parallel groups with 1:1 random allocation via chit method included 20 subjects (12 males and 8 females) with mean age of 58.6 years.

Case Group I: Each subject received single implant retained mandibular overdentures.

Control Group II: Each subject received two implant retained mandibular overdentures.

Patient consent: The proposed treatment modalities and alternatives were discussed with patients for this study. Explanatory consultation, treatment duration, prosthodontic restoration and possible complications as well as risks were all written in a consent form. The patients were fully informed about the possible consequences of the proposed clinical trial and signed a special written consent form designed for this purpose in accordance with the Declaration of Helsinki (2008). The consent forms were both in Hindi and English for better understanding by the patients.

\section{INCLUSION AND EXCLUSION Criteria}

Completely edentulous patients, co-operative patients, healthy patients without any systemic disease, patients with minimum $10 \mathrm{~mm}$ residual bone height available without augmentation, unsatisfied patients with old conventional complete dentures, patients without any bone disorders were included into the study. Exclusion Criteria includes patients with maxillofacial defects, patients suffering from systemic diseases, patients with any type of tumor, neurologic or cerebrovascular diseases or hemorrhagic or severe cardiopulmonary disorders and patients suffering from any neuromuscular disorders.

\section{Blinding}

Apparently, neither the participants nor care providers could be blinded as to the number of implants placed, but care providers were instructed not to comment about possible treatment outcomes to subjects. The denture retention was assessed by an independent assessor who was not aware of the type of intervention. The statistician was blinded.

\section{This study was conducted in 4 phases}

In the phase 1 clinical and radiographic diagnosis was done. In this phase, a single dental implant in the mid symphysis region was planned following all the surgical protocols after denture fabrication. Primary impressions were made from 
alginate. Impressions were poured with dental plaster and diagnostic cast were made. Border molding was performed with low fusing compound and final impressions were made with light body elastomeric impression material. Jaw relation and try-in was carried out. Dentures were fabricated with high impact heat cured acrylic resin and occlusion corrections were performed. Storage of maxillary and mandibular complete denture in $0.2 \%$ diluted solution of chlorhexidine and changing solution every alternate day.

In the phase 2 surgical procedures were carried out for all the subjects. After thorough clinical evaluation of the proposed implant site, midline in the case group and canine region bilaterally in the control group. a regular platform soft tissue level implant (Myriad, Netherland) with a diameter of 3.8 or $4.3 \mathrm{~mm}$ and 9.5 or $11 \mathrm{~mm}$ in length were selected according to patient requirement after evaluation prior to surgery. A retentive anchor with a titanium matrix ( $2 \mathrm{~mm}$ height) was selected for the prosthetic anchorage. After administration of anesthesia a crestal incision was made with two vertical releasing incisions in the bilateral canine area for patients of group II. For patients of group I, the crestal incision was made in the anterior midline area. A full thickness mucoperiosteal flap was reflected using a sharp mucoperiosteal elevator. Any crestal bone irregularity was adjusted with a bone file. For group II, a parallel pin was placed to ensure proper alignment of the osteotomy site. The osteotomy site was prepared according to the manufacture's direction using a standard bone drilling protocol, with extreme care to avoid penetration of the lingual or inferior cortex after raising mucoperiosteal flap. Initial implant stability was achieved with torques $>35 \mathrm{Ncm}$ and was tested manually by hand. Healing abutment of appropriate length was connected, and mucosa was approximated and sutured with (4-0) silk. Antibiotics (Augmentin $625 \mathrm{mg}$ ) and non-steroidal antiinflammatory (Ibrufen 400mg) medications were given to the patients 8 hourly for 5 days postoperatively. Immediately after surgery, all patients were allowed to take soft diet for 3 days and were also advised to maintain excellent oral hygiene. Digital Radiographic evaluations of bone were carried out immediately after implant placement and subsequently at $4 \& 12$ weeks of healing period.

In the phase 3 loading of the implant were carried out. Subsequent digital radiographs were taken at intervals of 4 weeks and 12 weeks after loading.

In the phase 4 digital intraoral peri-apical radiographs (RVG 5100) were used for measuring the bone level using measuring tool immediately after implant surgery, 1 month, 3 months, 4 months and 6 months and magnification error was checked. The data obtained was saved using Paint software used in Microsoft 8.1. The data so obtained for measuring the bone levels with the help of computer software (RVG 5100) was tabled. All data were statistically analyzed for result.

Method used for calculating crestal bone level at particular time will be given by Original crestal bone level at baseline $=($ radiographic crestal bone level $\times$ original or physical length of the implant body) / radiographic length of the implant body 4

Method used for calculating crestal bone loss
Crestal bone change or loss (at given time) = original
crestal bone level at baseline - crestal bone level at
that particular time 4
An analytical study was conducted on 8 edentulous subjects of which 5 were male and 3 were female. Measurements on implant length, magnification and crestal bone level were recorded at different time intervals to estimate crestal bone loss.

\section{RESULT}

The present study showed that there was a mean crestal bone loss of $0.71 \mathrm{~mm}$ between the tip of the implant and alveolar crest at the end of 6 months after implant placement in single implant group I [Table 1] while $0.67 \mathrm{~mm}$ in case of Group II two-implant retained mandibular overdentures [Table 2]. The percentage of crestal bone loss after 6 months follow up was $6.45 \%$ which is in Group I which was statistically insignificant compared to crestal bone loss in seen in Group II wherein $6.25 \%$ of bone loss was recorded [Table 3].

Table-1: Crestal Bone loss in Group I (single implant retained mandibular overdentures):

\begin{tabular}{|l|l|l|l|l|l|l|}
\hline \multirow{2}{*}{ Factor } & Parameter & $\begin{array}{l}\text { IMPLANT } \\
\text { PLACED }\end{array}$ & $\begin{array}{l}\text { 1st } \\
\text { MONTH }\end{array}$ & $\begin{array}{l}\text { 3rd MONTH } \\
\text { (IMPLANT LOAD) }\end{array}$ & $\begin{array}{l}\text { 4th } \\
\text { MONTH }\end{array}$ & $\begin{array}{l}\text { 6th } \\
\text { MONTH }\end{array}$ \\
\hline \multirow{2}{*}{$\begin{array}{l}\text { CRESTAL } \\
\text { BONE LOSS } \\
(\mathrm{mm})\end{array}$} & Mean & 0.00 & 0.34 & 0.52 & 0.57 & 0.70 \\
\cline { 2 - 8 } & SD & 0.00 & 0.16 & 0.12 & 0.07 & 0.06 \\
\cline { 2 - 8 } & Min & 0.00 & 0.07 & 0.37 & 0.46 & 0.62 \\
\cline { 2 - 8 } & Max & 0.00 & 0.50 & 0.70 & 0.70 & 0.78 \\
\hline
\end{tabular}


Table-2: Crestal Bone loss in Group II (two implant retained mandibular overdentures)

\begin{tabular}{|l|l|l|l|l|l|l|}
\hline \multirow{2}{*}{ Factor } & \multirow{2}{*}{ Parameter } & $\begin{array}{l}\text { IMPLANT } \\
\text { PLACED }\end{array}$ & $\begin{array}{l}\text { 1st } \\
\text { MONTH }\end{array}$ & $\begin{array}{l}\text { 3rd MONTH } \\
\text { (IMPLANT LOAD) }\end{array}$ & $\begin{array}{l}\text { 4th } \\
\text { MONTH }\end{array}$ & $\begin{array}{l}\text { 6th } \\
\text { MONTH }\end{array}$ \\
\hline \multirow{3}{*}{$\begin{array}{l}\text { CRESTAL BONE } \\
\text { LOSS }(\mathrm{mm})\end{array}$} & Mean & 0.00 & 0.32 & 0.51 & 0.54 & 0.67 \\
\cline { 2 - 8 } & SD & 0.00 & 0.12 & 0.13 & 0.06 & 0.05 \\
\cline { 2 - 8 } & Min & 0.00 & 0.06 & 0.37 & 0.46 & 0.60 \\
\cline { 2 - 8 } & Max & 0.00 & 0.49 & 0.68 & 0.68 & 0.72 \\
\hline
\end{tabular}

Table 3: Comparative evaluation of Group I versus Group II

\begin{tabular}{|l|l|l|l|}
\hline Follow-up periods & Group I (Mean \pm SD) & Group II $($ Mean \pm SD) & P value \\
\hline Baseline & $(0.34 \pm 0.16)$ & $(0.32 \pm 0.51)$ & $>0.05$ \\
\hline 1 month & $(0.52 \pm 0.12)$ & $(0.51 \pm 0.13)$ & $>0.05$ \\
\hline 3 month & $(0.57 \pm 0.70)$ & $(0.54 \pm 0.06)$ & $>0.05$ \\
\hline 6 month & $(0.70 \pm 0.06)$ & $(0.67 \pm 0.05)$ & $>0.05$ \\
\hline \multicolumn{2}{|l}{ P value was statistically non-significant }
\end{tabular}

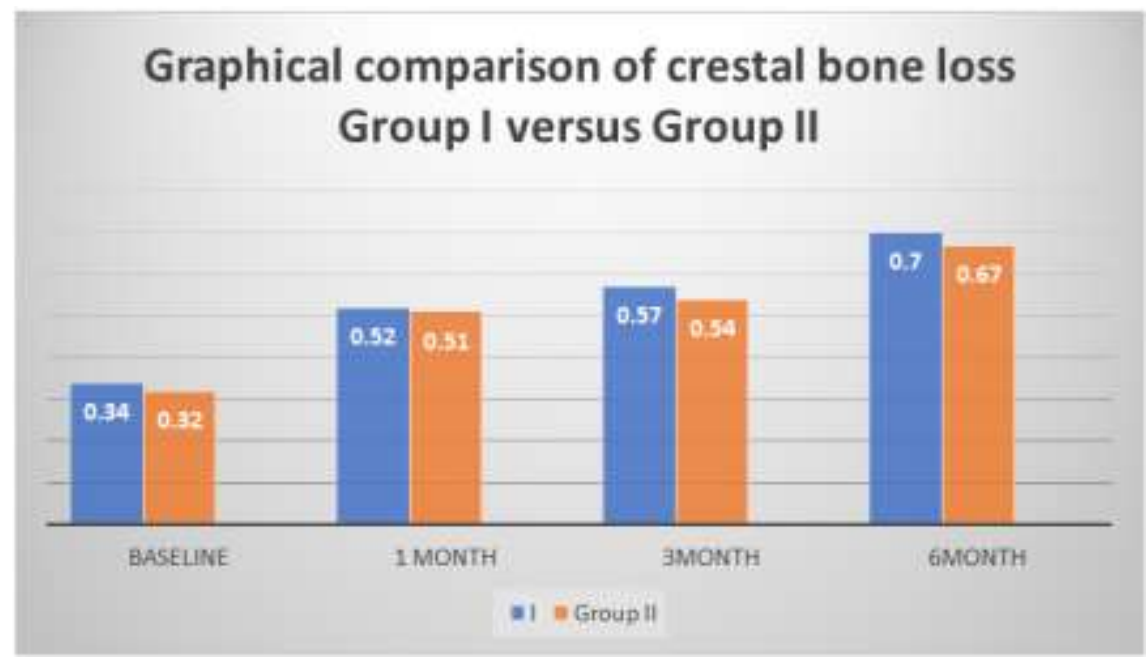

Graph-1: Graphical comparison of crestal bone loss Group I versus Group II

\section{DISCUSSION}

Rehabilitation using complete dentures on edentulous patients who suffer from a compromised alveolar bone often results in denture soreness, poor retention, instability, unclear pronunciation, and low chewing efficiency. Implant-retained overdentures are widely applied for the rehabilitation of edentulous jaws as it is able to increase retention rates of prosthesis, enhance the masticatory function and reduce the absorption of alveolar bone by regulating neuromuscular adaptation.

Compared to the conventional complete denture, two or more implant-retained mandibular overdentures can promote function and enhance success rates. The York consensus statement recommends at least two implants to support mandibular overdentures for edentulous patients. However, economic constraints especially among the emerging elderly population in developing countries make this treatment strategy financially challenging. In order to reduce the cost and time of treatment, the concept of single implant-retained overdentures provides another option for elderly populations. Single implant retained overdentures have advantages over two implant retained overdentures. Two implant retained overdentures require the implant to be parallel to each other, be equidistant from the midline, at the same level, and failure of one may lead to unequal stresses on the other. These are avoided in case of a single implant retained overdentures. According to Tokuhisa et al. the use of ball O-ring attachment could be advantages for implant supported overdentures about optimizing stress and minimizing denture movement in comparison to bar attachment and magnets [8].

The longevity of dental implants is highly dependent on integration between implant components Gand oral tissues, including hard and soft tissues. Initial breakdown of the implant-tissue interface generally begins at the crestal region in successfully osseointegrated endosseous implants. Many possible etiologies of early crestal bone loss around implants (from implant placement to 1-year post-loading) including surgical trauma, occlusal overload, periimplantitis, the presence of microgap, reformation of biologic width, implant crest module, and others have been proposed. However, the location of dental 
implants, whether subcrestal or supracrestal, is still becoming increasing importance for researchers.

Submerged titanium implants had 0.9 to 1.6 $\mathrm{mm}$ marginal bone loss from the first thread by the end of the first year in function, while only 0.05 to $0.13 \mathrm{~mm}$ bone loss occurred after the first year. Based on the findings on submerged implants, Albrektsson et al. proposed criteria for implant success, including a vertical bone loss of less than $0.2 \mathrm{~mm}$ annually following the implant's first year of function [9]. F.Vafaee et al. in their study found that marginal bone loss was $0.5 \mathrm{~mm}$ at the end of 6 months in single implant retained mandibular overdenture [10]. Studies reported that radiographic measurement of crestal bone loss by Intraoral Periapical (IOPA) radiographs are subject to change at each appointment. Previous studies like JiHoon described a conventional technique to assess crestal bone changes by measuring the distance between the first screw thread of the endosseous implant to the top of the alveolar crest [11]. The main disadvantage of this technique is to precisely measure crestal bone loss as the distance is very small to calculate between those two points.

To minimize inconsistencies and measurement errors, Pravin Kumar G. Patil and Smita Nimbalkar proposed a method to measure the radiographic crestal bone level from the tip of the implant body to the top of the alveolar crest instead of the first thread of the implant to the alveolar crest. As the distance between the first thread and alveolar crest was much less and could not be measured precisely [12].

Finding and observations of our study is in accordance with observations made by AJ. Flichy Fernandej et al. which shows that after 6 months, bone loss was $0.80 \pm 1.04 \mathrm{~mm}$ on mesial side and $0.73 \pm 1.08$ $\mathrm{mm}$ on distal side, while after 12 months bone loss was $0.92 \pm 1.02$ mesially and $0.87 \pm 1.01$ distally [13]. The observation made in the study by F. Vafaee et al. which was $0.5 \mathrm{~mm}$ at the end of 6 month is also comparable to finding of our study. The findings in the study of Guruprasad for crestal bone loss were $0.74 \mathrm{~mm}$ which supports the finding of our study [14].

\section{CONCLUSION}

The study results showed no significant difference in crestal bone loss in the two groups suggesting two implant systems can be replaced by single implant supported overdentures in cases of low Single implant retained mandibular overdentures could be used as another alternative treatment option for completely edentulous elderly patients with severely resorbed ridges and financially and systemically compromised conditions. The scope of single implant retained overdentures can be a promising alternative for patients with an atrophic mandible, systemically compromised patients with financial difficulties [15].
We can conclude that the single implant supported overdentures is a good treatment option for severely resorbed, financially and systemically compromised completely edentulous patients of developing countries like us. The limitation of this study was small sample size with short duration of 6 months follow up period.

\section{Future perspectives}

There is a need for further studies with a greater number of sample size and longer duration follow up, to confirm the results of this study for measuring and calculating crestal bone loss in single implant supported overdentures.

\section{REFERENCES}

1. Cheng, T., Ma, L. I., Liu, X. L., Sun, G. F., He, X. J., Huo, J. Y., \& Wang, Y. N. (2012). Use of a single implant to retain mandibular overdenture: A preliminary clinical trial of 13 cases. Journal of Dental Sciences, 7(3), 261-266.

2. Sethi, T., Kheur, M., Harianawala, H., Jambhekar, S., Kantharia, N., \& Sandhu, R. (2014). Immediate loading of a single implant retained mandibular complete denture utilizing a magnetic attachment: A case report. J Dent Appl, 1, 33-6.

3. Dannan, A. (2012). Crestal bone loss around dental implants; a short communication. Internet Journal of Dental science, 10(2).

4. Feine, J. S., Carlsson, G. E., Awad, M. A., Chehade, A., Duncan, W. J., Gizani, S., ... \& Mojon, P. (2002). The McGill consensus statement on overdentures. Mandibular two-implant overdentures as first choice standard of care for edentulous patients. Montreal, Quebec, May 24-25, 2002. The International journal of oral \& maxillofacial implants, 17(4), 601.

5. Thomason, J. M., Feine, J., Exley, C., Moynihan, P., Müller, F., Naert, I., ... \& Lynch, C. (2009). Mandibular two implant-supported overdentures as the first choice standard of care for edentulous patients-the York Consensus Statement. British dental journal, 207(4), 185-186.

6. Cordioli, G., Majzoub, Z., \& Castagna, S. (1997). Mandibular overdentures anchored to single implants: a five-year prospective study. The Journal of prosthetic dentistry, 78(2), 159-165.

7. Leung, K. C., Chow, T. W., Wat, P. Y., \& Comfort, M. B. (2001). Peri-implant bone loss: management of a patient. International Journal of Oral and Maxillofacial Implants, 16(2), 273-277.

8. Tokuhisa, M., Matsushita, Y., \& Koyano, K. (2003). In Vitro Study of a Mandibular Implant Overdenture Retained with Ball, Magnet, or Bar Attachments: Comparison of Load Transfer and Denture Stability. International Journal of Prosthodontics, 16(2).

9. Albrektsson, T., Buser, D., \& Sennerby, L. (2012). Crestal bone loss and oral implants. Clinical 
implant dentistry and related research, 14(6), 783791.

10. Vafaee, F., Khoshhal, M., Tavakolizadeh, S., Ebrahimzadeh, Z., Kadkhodazadeh, M., \& Torkzaban, P. (2011). Single implant retained mandibular overdenture with immediate loading (case report). Research Journal of Medical Sciences, 5(5), 273-275.

11. Park, J. H., Kim, Y. K., Yun, P. Y., Yi, Y. J., Yeo, I. S., Lee, H. J., \& Park, J. Y. (2009). Analysis of factors affecting crestal bone loss around the implants. J Kor Dent Sci, 3(1), 12-17.

12. Patil, P. G., \& Nimbalkar-Patil, S. (2015). A radiographic measurement technique for crest bone changes related to dental implants. Journal of prosthetic dentistry, 113(4), 350-351.
13. Flichy Fernández, A., Ata-Ali Mahmud, F. J., Palma Carrió, C., Peñarrocha Oltra, D., Conejero, J., \& Peñarrocha Diago, M. (2011). Radiological assessment of peri-implant bone loss: a 12-month retrospective study.

14. Thapliyal, G. K., \& Pawar, V. R. (2013). A comparative analysis of periimplant bone levels of immediate and conventionally loaded implants. Medical journal armed forces india, 69(1), 41-47.

15. Kishore, K., Anne, G., Mohan T, K., Kumar K, S., Dev J, R. R., \& Devi, N. (2014). Evaluation Of Crestal Bone Loss Around Two Different Implant Systems Supporting A Mandibular Overdenture-A Clinical Study. Indian Journal of Dental Sciences, 6(2). 